\title{
BIM 技术在绿色建筑设计中的应用探究
}

\author{
夏小强 \\ 天津市美兴建筑设计事务所(普通合伙) \\ DOI:10.32629/btr.v2i8.2449
}

[摘要] 建筑行业蓬勃发展下, 大量新技术、新工艺和新材料应用其中,绿色建筑逐渐成为建筑行业主流趋势, 如何打造高质量 的绿色建筑, 对建筑企业市场竞争优势提升具有重要作用。在绿色建筑设计中, 通过 BIM 技术的应用, 整合建筑相关资料, 结合 区域实际情况优化设计方案,构建三维建筑信息模型,提升设计合理性的同时,最大程度上降低资源损耗和环境污染。本文就绿 色建筑设计中 BIM 技术应用进行探究,分析其中的不足,充分发挥BIM 技术优势,推动绿色建筑建设和发展。

[关键词] 绿色建筑; 建筑设计; BIM 技术; 应用

在可持续发展背景下, 世界各国面临着能源短缺和环境 污染严峻的问题, 而建筑行业需要大量能源支持, 首当其冲, 推行绿色建筑很有必要。面对激烈的市场竞争, 建筑企业想 要谋求可持续发展, 需要正确看待绿色建筑重要性, 结合可 持续发展战略要求, 优化绿色建筑设计。在绿色建筑设计中, 通过BIM技术的应用, 整合建筑工程相关资料信息, 建立三维 建筑信息模型, 对数据深入统计和分析, 模拟分析可能出现 的问题, 调整设计方案, 在保证建筑工程质量和安全前提下, 最大程度上降低建筑能耗和环境污染, 对建筑企业健康持续 发展意义深远。

\section{1 绿色建筑和 BIM 技术概述}

绿色建筑是建筑行业的主流趋势, 是指在建筑全生命周 期内, 合理配置土地资源、水资源、原材料和能源, 减少资源 损耗和环境污染的同时, 为人们营造健康、舒适的生活环境, 构建环境友好型建筑。

BIM技术作为一种前沿技术, 是指建筑信息模型, 可以有 效整合建筑资源, 实现信息共建共享, 为建筑设计和拆除全 生命周期提供可靠数据依据, 做出合理的决策 ${ }^{[1]}$ 。通过整合 建筑工程各个阶段信息, 依托于BIM技术实现, 客观反映建筑 施工情况, 以便于推动绿色建筑建设和发展。

\section{2 绿色建筑设计中 BIM 技术应用意义分析}

绿色建筑是在建筑工程设计和施工中, 渗透节能环保理 念, 促使建筑与自然环境有机结合, 在满足建筑工程质量和 安全需要的同时, 减少资源损耗和环境污染, 迎合建筑行业 的主流发展趋势。遵循节能环保理念, 采用节能环保型建材 和绿色生产方式, 通过合理规划和利用, 有助于减少资源损 耗和环境污染 ${ }^{[2]}$ 。尤其是在绿色建筑设计行业中, 需要相关 工作人员予以高度关注和重视, 转变工作理念, 引入绿色建 筑材料和技术, 打造绿色建筑。而BIM技术尽管在我国起步较 晚, 尚未建立完善的标准体系, 但是有着很大的发展空间, 在 绿色建筑设计中广泛应用BIM技术, 对于打造高质量的绿色 建筑意义深远。

\section{3 绿色建筑设计中 BIM 技术的应用困境}

纵观当前绿色建筑设计现状来看, 受到传统理念影响,
其中还有很多不足暴露出来, 影响到绿色建筑设计合理性, 具体表现在以下几个方面:

\section{1 现有绿色工程建设体制不健全}

伴随着城市现代化建设进程不断加快, 绿色建筑呈现良 好的发展前景, 尤其是新技术和新材料的应用, 为新时期的建 筑行业发展指明了新的前进方向。但是, 我国的绿色建筑起步 时间较晚, 容易受到市场经济影响较大, 现有的工程建设体制 不健全, 极大的制约现代建筑行业健康持续发展 ${ }^{[3]}$ 。在可持续 发展背景下, 为了推动绿色建筑建设和发展, 开始在全国范围 内推行绿色建筑试点, 但是部分建筑企业为了追求利益, 却忽 视了绿色建筑原有价值发挥, 阻碍绿色建筑发展。

\section{2 评价体系不完善}

我国是一个发展中国家, 相较于发达国家, 绿色建筑发 展进程缓慢, 尚未建立完善的绿色建筑评价体系。通过科学 合理的评价方式, 对绿色建筑节能效果定量分析, 有助于降 低绿色建筑能耗和环境污染, 合理配置资源, 为后续的绿色 建筑设计和施工提供支持, 编制切实可行的设计方案 ${ }^{[4]}$ 。但 是, 当前我国现有的绿色建筑评价体系还有很多不足, 各个 环节联系不充分, 即便建筑评价体系不断更新, 但是较之西 方发达国家还有不足, 影响到绿色建筑设计和发展。

\section{3绿色建筑专业协同性不足}

绿色建筑设计是一项专业性较强的工作, 其中涉及到众 多内容, 包括建筑设计、结构设计和机电设计等众多内容, 在满足建筑质量和安全需要的同时, 灵活选用节能环保型材 料, 降低资源损耗和环境污染。在建筑工程设计中, 部分单位 在各专业协调方面作用发挥不充分, 专业协同性不足, 不仅 影响到信息共建共享, 还会影响到整体建筑工程质量, 制约 建筑行业健康持续发展 ${ }^{[5]}$ 。

与此同时, 建筑设计环节与施工环节联系不充分, 设计 人员并未充分了解到施工区域实际情况, 受到陈旧理念束缚 和影响, 绿色建筑设计存在很大偏差, 制约后续施工活动有 序展开。部分设计人员对施工内容了解不充分, 施工经验不 足, 绿色建筑设计中存在很多问题, 未能寻求合理措施针对 性解决。加之施工人员专业能力和职业素养不高, 未能积极 
参加专业培训, 所以对BIM技术、信息技术掌握不充分, 影响 到绿色建筑设计合理性。

\section{4 绿色建筑设计中 BIM 技术的应用途径}

4. 1 建立建筑信息模型

在绿色建筑设计中应用BIM技术, 需要转变工作理念, 提 升BIM技术和绿色建筑认知, 整合建筑工程全生命周期信息, 贯穿于建筑工程全过程。依托于BIM技术, 可以整合绿色建筑 信息, 建立建筑信息模型, 模拟后期施工全过程, 优化图纸设 计的同时, 计算工程各个构件参数。结合绿色建筑实际情况, 优化绿色建筑各个环节, 在信息共享平台上动态调整建筑结 构信息参数, 以便于提升绿色建筑设计质量, 指导后续绿色 建筑工程施工活动有序展开 ${ }^{[6]}$ 。另外, 设计人员应提升自身 专业能力和职业素养, 熟练掌握BIM技术进行绿色建筑设计, 把握建筑各个环节, 实现建筑节能环保, 打造高质量的绿色 建筑。

4. 2 合理配置和利用资源材料

在绿色建筑设计中, 设计人员应转变工作理念, 严格遵 循绿色建筑设计标准, 整合建筑材料资源, 获取精准、全面的 建筑信息, 为后续的管理决策提供可靠数据依据。通过BIM 技术的应用, 可以改善传统计算方式不足, 借助先进技术和 设备来统计材料数据, 精准、快速计算不同材料用量, 为后续 绿色建筑工程施工活动有序开展提供坚实保障 ${ }^{[7]}$ 。另外, 充 分发挥BIM技术优势, 对绿色建筑构件参数精准计算, 将建筑 多专业设计内容整合在一起, 协调解决各专业矛盾冲突, 提 升资源利用效率的同时, 最大程度上减少环境污染和破坏。

\section{3有效分析和配置室内环境}

在绿色建筑设计中, 设计是否合理直接影响到室内环境, 需要综合考量和分析室内环境的声、光和风要素, 结合标准 动态调整。室内光环境和照明结构联系密切, 由于照明结构 设计不合理, 可能影响到自然光资源的合理利用, 增加建筑 能耗。通过建立自然通风模型, 分析室内污染物分布和空气
流动情况, 结合具体需要动态调整室内通风位置, 改善室内 环境质量。同时, 建立三维建筑信息模型, 结合相关标准规范 来整合与分析气象数据, 可视化模拟绿色建筑, 优化绿色建 筑工程方案, 调整结构参数, 实现建筑能耗有效控制。通过 BIM技术, 对室外紫外线辐射强度综合分析, 编制合理的设计 方案, 实现资源的最大化配置和利用, 满足室内照明需要。

此外, 应该进一步加强工作人员专业培训, 夯实专业知 识和技能, 学习如何灵活运用BIM技术设计建筑方案, 并结合 建筑环境综合分析, 降低建筑能耗和环境污染的同时, 打造 环境友好型建筑。只有这样, 才能实现资源合理开发和利用, 打造高质量的绿色建筑, 推动建筑行业健康持续发展。

\section{5 结论}

综上所述, 面对现代建筑行业飞快发展带来的挑战, 绿 色建筑作为主流趋势, 有助于整合建筑工程资源, 在满足绿 色建筑设计和建设需要的同时, 最大程度上降低能源浪费和 环境污染, 实现资源最大化利用, 打造节能型建筑。

\section{[参考文献]}

[1]熊康.绿色建筑背景下基于 BIM 技术的建筑工业化发 展机制研究[J].江西建材,2019,12(06):202-203.

[2]于戈.浅谈绿色建筑技术在暖通空调设计中的应用 [J].四川建材,2019,45(06):170-171.

[3]刘博. 当前绿色建筑节能设计中 BIM 技术的应用探讨 研究[J].现代物业(中旬刊),2018,29(10):68.

[4]周桂香, 蒋凤昌,朱水勇, 等.BIM 技术在绿色医院建筑 设计阶段的应用研究[J]. 江苏科技信息,2019,36(09):44-46.

[5]刘文雅,李楠楠.绿色建筑设计中 BIM 技术应用分析一 一以北京绿地中心工程为例 [J]. 居舍,2019,20(06):112+127.

[6]杨传光.基于BIM技术的绿色建筑设计施工一体化应 用 [J].自动化与仪器仪表,2018,12(12):226-228。

[7]徐莉.基于BIM技术的绿色建筑设计应用研究一以江苏城乡建 设职业学院研发楼设计为例[J].江苏建筑,2018,16(1):132-134+146. 